Advanced Library Skills for Physics Research 



\title{
Advanced Library Skills for Physics Research
}

\author{
LAUREN STIEGLITZ
}




\section{(ㄷ) (1)}

Advanced Library Skills for Physics Research by Lauren Stieglitz is licensed under a Creative Commons Attribution 4.0 International License, except where otherwise noted. 


\section{Contents}

Introduction 1

Part I. Evaluating Information

1. Evaluating Information 5

2. The CRAAP Test 7

3. Exercise: Evaluating an Article 9

4. Evaluating a Journal 11

5. Science and Science News 16

Part II. Predatory Publishing

6. Predatory Publishing 21

7. Open Access 25

8. Identifying Predatory Publishers 29

9. Hijacked Journals 33

Part III. Advanced Literature Searching

10. Where to Search 39

11. Building a Search 45

12. Searching Preprint Servers - arXiv 52

13. Searching Academic Databases - Web of Science 56

14. Searching Google Scholar 62

15. Recommended Databases by Discipline 66 
16. More Literature Searching Tips 71

17. Accessing Library Materials Remotely 74

Part IV. Citation Management and Avoiding

$\underline{\text { Plagiarism }}$

18. Citation Management 79

19. Citation Management with Zotero 81

20. Citing in LaTeX 86

21. Avoiding Plagiarism 88

$\begin{array}{ll}\text { Getting Help } & 91\end{array}$ 
This tutorial is your guide to use the library like a pro. It covers all of the information you need to find, evaluate and organize research materials. This tutorial is designed for upper-level undergraduate students and graduate students conducting research in physics.

By the end of this tutorial, you will be able to:

- Critically evaluate information

- Identify and avoid predatory publishers

- Know where to search for relevant resources

- Apply advanced literature searching techniques

- Use a citation managers to effectively organize and cite materials

\section{Contents:}

\section{Introduction}

I. Evaluating Information

1. Evaluating Information

2. The CRAAP Test

3. Exercise: Evaluating an Article

4. Evaluating a Journal 
5. Science and Science News

II. Predatory Publishing

6. Predatory Publishing

7. Open Access

8. Identifying Predatory Publishers

9. Hijacked Journals

III. Advanced Literature Searching

10. Where to Search

11. Building a Search

12. Searching Preprint Servers - arXiv

13. Searching Academic Databases - Web of

$\underline{\text { Science }}$

14. Searching Google Scholar

15. Recommended Databases by Discipline

16. More Literature Searching Tips

17. Accessing Library Materials Remotely

IV. Citation Management and Avoiding Plagiarism

18. Citation Management

19. Citation Management with Zotero

20. Citing in LaTeX

21. Avoiding Plagiarism

Getting Help 
Use your left and right arrow keys to go from page to page, or click the blue buttons at the bottom of the page

Go directly to a specific chapter with the Contents bar at the top of the page

\section{CONTENTS}





\section{PART I}

\section{EVALUATING \\ INFORMATION}

This section covers information evaluation, so that you are using the best information for your research.

$\underline{\text { I. Evaluating Information }}$

2. The CRAAP Test

3. Exercise: Evaluating an Article

4. Evaluating a Journal

5. Science and Science News 



\section{Evaluating Information}

After completing this chapter you will :

- Understand the importance of evaluating information

- Evaluate resources and information for your research

- Evaluate journals and understand Journal Impact Factors

- Understand how science is presented and sometimes misinterpreted in the media

Why do we evaluate information?

We evaluate information to make sure that we are using the best resources in our research. Over 3 million research articles are published a year ${ }^{1}$. With so much information out there, it is important to critically examine each resource before you use it in your work.

We want to find information is high quality and relevant.

This section will teach you what to look for when you are evaluating resources. 


\section{Why is this important?}

Though most journal articles contain reliable information, not all journal articles have the same level of quality and some can have bad information. That is why we need to examine every article critically.

Look at the following slideshow for examples of why an article may not be reliable:

圈 An interactive or media element has been excluded here:

https://openeducationalberta.ca/advancedlibsearch/?p=5

1. International Association of Scientific, Technical and Medical Publishers. (2018). STM Report: An overview of scientific and scholarly publishing (5th edition). https://www.stm-assoc.org/2018_10_04_STM_Report_2018.pdf 


\section{The CRAAP Test}

The CRAAP Test

We can use the CRAAP Test to evaluate resources. When you are deciding whether to use a resource, ask yourself the following questions:

Currency - Is it timely?

Relevance - Useful for your purposes?

Authority - Who? What is the source?

Accuracy - Are there references to back it up?

Purpose - Why? Is there a bias?

For more detailed information, examine the drop down explanations below:

An interactive or media element has been excluded

드스 from this version of the text. You can view it online here:

https://openeducationalberta.ca/advancedlibsearch/?p=29

Steps to Evaluate an Article

- Read the abstract first: the abstract summarized the articles 
findings, so this will help you decide whether you want to read the full article

- Skim the article: Skim the article the first time, to see if the article passes your CRAAP test. Next, read more closely the second time and take notes

- Follow up references: you can check an articles to see if the author has used reputable sources and you can find more articles that may be useful

- See who cited an article: in some databases (Web of Science, Scopus), you can see the list of other articles that cite the article. You can also sort search results by number of citations to find highly cited, potentially important papers (note: be careful some articles are highly cited because they are contentious)

- Critically evaluate each resource you use

- What makes a "good" resource can be different depending on your needs:

- Are you looking for cutting-edge information or background information?

- Are you looking for technical information or general information

- Look for peer reviewed articles, as peer reviewed materials is more reliable 


\section{Exercise: Evaluating an Article}

Would you use the following article for a paper or assignment on Newtonian physics?

Article: Are Newtonian Gravitation and Geometrized Newtonian Gravitation Theoretically Equivalent?

Webpage (log in to view article): https://doi.org/10.1007/ s10670-015-9783-5

Open Access version: https://arxiv.org/pdf/1411.5757.pdf

\section{Instructions:}

- Take a look at the article and decide whether it is appropriate for a physics student

- Look at the highlighted details below for tips on what to look for

An interactive or media element has been excluded from this version of the text. You can view it online here:

https://openeducationalberta.ca/advancedlibsearch/?p=34 


\section{Conclusion}

This article is not appropriate for a physics assignment

- The author is a professor at a prestigious university, but they are a professor of Philosophy not Physics

- The journal is a well-regarded journal, but it is for Scientific Philosophy not Physics

- The article is not relevant to a physics course, thought it may be an otherwise great article

Tips

When evaluating material it is most important to evaluate its quality and relevance

10 | Exercise: Evaluating an Article 


\section{Evaluating a Journal}

When evaluating an article, it is also important to take a look at the journal it is published in. Evaluating journals is also important when you decide where you want to publish your research.

What to look at when evaluating journals:

- Journal Impact Factor - a metric measuring how much impact a journal has

- Journal publisher - organization or company that publishes the journal

- Journal editorial board - the researchers who are editors for the journal

\section{Journal Impact Factor}

The Journal Impact Factor (JIF) is measure of the impact of a particular journal in its field. The Journal Impact Factor is defined as the number of citations received in an a year by articles published in that journal during the two preceding years, divided by the total number of "citable items" published in that journal during the two preceding years.

\section{Calculation:}

2018 Impact Factor $=\mathrm{A} / \mathrm{B}$

$A=$ the number of times articles published in 2016 and 2017 were cited during 2018 $\mathrm{B}=$ the total number of "citable items" published in 2016 and 2017 


\section{Finding Impact Factor}

Journal Impact Factors can be found in the Clarivate Analytics Journal Citation Report. You can search by journal title or browse by subject area

\section{Welcome to Journal Citation Reports}

\section{Search a journal title or select an option to get started}

Enter a journal name

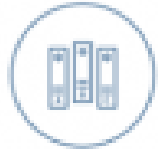

Browse by Journal

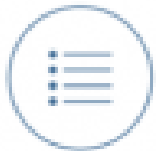

Browse by Category

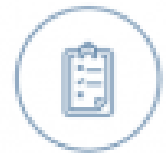

Custom Reports

Journal Citation Reports homepage

12 | Evaluating a Journal 


\section{Journal Titles Ranked by Impact Factor}

\begin{tabular}{|c|c|c|c|c|}
\hline \multicolumn{2}{|c|}{ Compare Selected Journais } & \multicolumn{3}{|c|}{ Add Journals to New or Existing List } \\
\hline $\begin{array}{l}\text { Select } \\
\text { All }\end{array}$ & & Full Joumal Tite & Total Cites & $\begin{array}{l}\text { Journal } \\
\text { limpact } \\
\text { Factor * }\end{array}$ \\
\hline$\square$ & 1 & $\begin{array}{l}\text { REVIEWS OF MODERN } \\
\text { PHYSICS }\end{array}$ & 51,122 & 45.037 \\
\hline$\square$ & 2 & $\begin{array}{l}\text { PHYSICS REPORTS-REVIEW } \\
\text { SECTION OF PHYSICS } \\
\text { LETTERS }\end{array}$ & 28,867 & 25.798 \\
\hline 무 & 3 & Nature Physics & 37,111 & 19.256 \\
\hline E & 4 & $\begin{array}{l}\text { REPORTS ON PROGRESS IN } \\
\text { PHYSICS }\end{array}$ & 18,766 & 17.032 \\
\hline 무 & 5 & Physical Review $X$ & 16,532 & 12.577 \\
\hline 区 & 6 & PHYSICAL REVIEW LETTERS & 443,084 & 8.385 \\
\hline
\end{tabular}

List of journals in the Physics, Multidisciplinary category, sorted by Journal Impact Factor

\section{Caveats:}

- Impact Factor is comparable only for journals in the same field, you can't compare impact factors between categories on Journal Citation Reports

- Journals with a general focus have higher Journal Impact Factors than journals with a specialized focus (ie Nature has 2019 JIF of 42.8, while Nature Astronomy has a 2019 JIF of 11. 5)

- Impact Factor is higher for review journals, as review articles get more citations than regular articles ( 5 out of 6 high impact journals in the image above are review journals)

- Journals can "game the system" to increase their Impact Factor (i.e. increasing journal self-citations or publishing more "noncitable items" that still get citations) 
The Journal Impact Factor is useful to get an understanding of the importance and impact of a journal in it's field, but it is not a measure of quality and it is not the only factor you should consider when evaluating a journal. A journal with a higher Impact Factor is not necessarily "better" than a journal with a lower Impact Factor.

\section{Journal Publisher}

Many journals are published by large academic publishers (like Elsevier or Springer Nature) or by research societies and professional organizations. Look for journals published by societies or organizations that are important to your field.

Be cautious of journals published by organizations or publishers you have never heard of. When in doubt, look up the publisher.

\section{Journal Editorial Board}

The editorial board of a journal is made up of researchers relevant to that journal. When evaluating a journal, take a look at the editorial board to see if it includes any researchers whose names or reputations you recognize.

\section{Think. Check. Submit}

Think. Check. Submit. is a resource that can help you evaluate journals when your publishing research. Use their checklist to evaluate a journal, or watch the video below: 


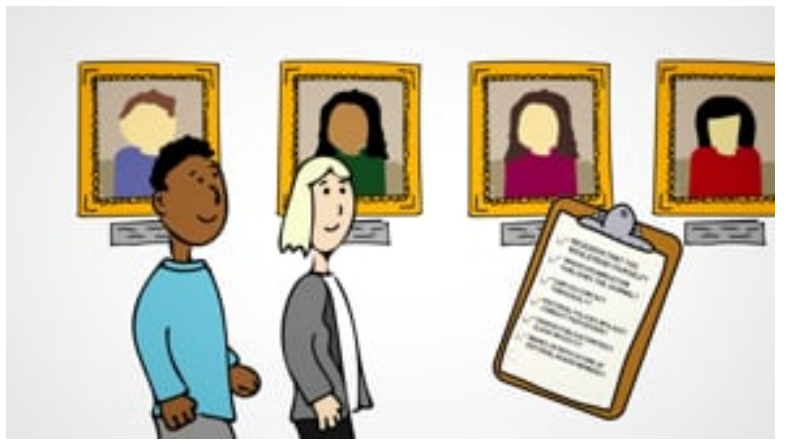

A Vimeo element has been excluded from this version of the text. You can view it online here:

https://openeducationalberta.ca/advancedlibsearch/?p=53

What about Predatory Publishers

It is also useful to evaluate journals to avoid predatory publishers

We'll cover predatory publishing in Section II 


\section{Science and Science News}

Press releases and science news play an important role in the dissemination of research to the public. Press releases and the new articles based on them are the primary way that the public learns about advances in scientific research.

Press releases and science news stories can also be a great way for students and researchers to learn about new research, but they can over-simplify information for a non-scientific audience and can sometimes exaggerate or misinterpret findings.

When evaluating information, we need to be aware of how scientific information can be portrayed, and sometimes misconstrued, in press releases and in the news.

\section{How does it work?}
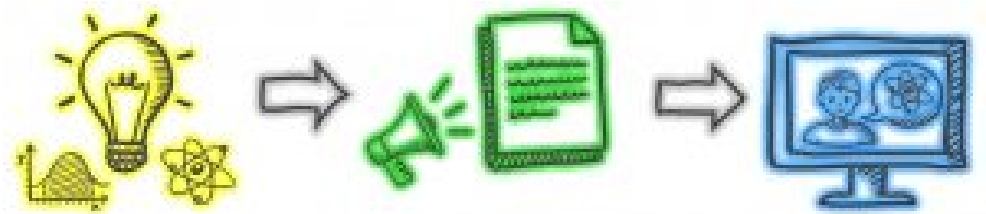

Step 1: Researchers share their their findings in an academic publication or at a conference.

Step 2: The researcher's university or research institute puts out a press release to promote that research and hopefully convince the press to write about it. Press releases translate research for a nonacademic audience and information can be generalized or lost in translation.

Step 3: News outlets take press releases as the basis of for science stories. The researcher's findings will be further translated for a general audience. Sometimes research can be exaggerated to generate "click bait" or misinterpreted by non-experts and this can result in the misrepresentation of the original research. 
For example, the research study "Positive Selection on a Regulatory Insertion-Deletion Polymorphism in FADS2 Influences Apparent Endogenous Synthesis of Arachidonic Acid" becomes the news article "Being a vegetarian could kill you, science warns." See below for a more detailed example.

\section{Example: The Benefits of Chocolate During Pregnancy}

In 2016, a group of researchers presented their study, High-flavanol chocolate to improve placental function and to decrease the risk of preeclampsia: a double blind randomized clinical trial, at a conference. They found "no difference" in preeclampsia risk in their study groups, yet the media reported a decrease in preeclampsia risk.

The slides below show how the research was presented originally, in the press-release about the study and in the media:

An interactive or media element has been excluded
from this version of the text. You can view it online
https://openeducationalberta.ca/advancedlibsearch/?p=62

\section{Using Press Releases and News Stories}

Press releases and news stories can be a great way to learn about new research advances, but we need to be aware of the limitations demonstrated above.

Always critically evaluate the information presented and make sure to check the original research. Press releases and news stories 
often link to the original research article, so you can easily find the original research study and use it in your own work.

\section{Tips}

- $\quad$ Use the CRAAP test to evaluate information in press releases or the news

- $\quad$ After reading the press release or news article that interests you, always read the original research 


\section{PART II \\ PREDATORY PUBLISHING}

This section covers predatory publishing, including how to identify and avoid predatory publishers

6. Predatory Publishing

7. Open Access

$\underline{\text { 8. Identifying Predatory Publishers }}$

2. Hijacked Journals 



\section{Predatory Publishing}

After completing this chapter you will be able to:

- Identify and avoid predatory publications

- Understand the issues with predatory publishers

- Understand Open Access publishing models

\section{What are predatory publishers?}

Predatory publishers are exploitative publishers that take advantage of the Open Access publishing model. They charge publication fees (article processing charges or APCs) to authors, but they forgo the peer review and editorial services of legitimate Open Access publishers.

Predatory publishers try to trick researchers into thinking they are legitimate, some techniques include:

- Having names that are very similar to the names of legitimate journals

- Sending enticing spam emails to researchers

- Copying the name and information of legitimate journals (see Ch 9. Hijacked Journals) 


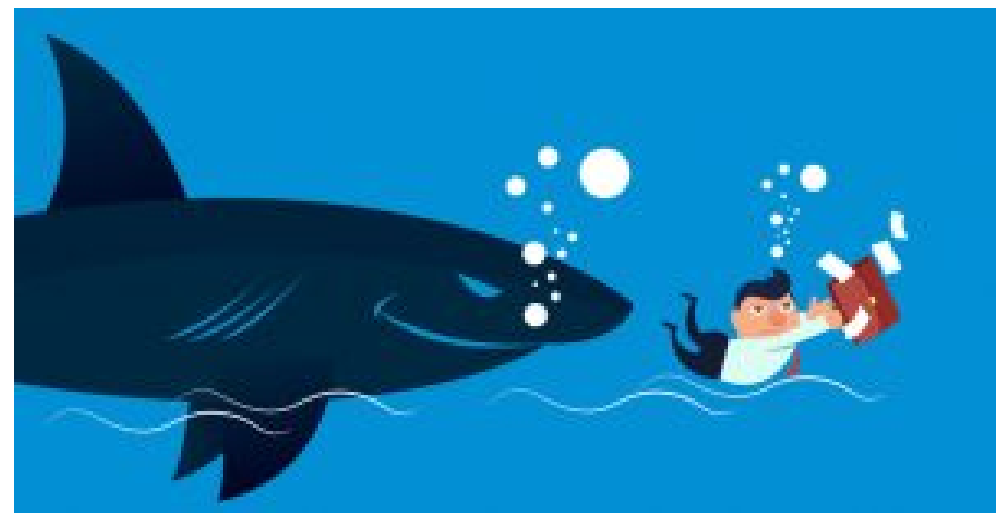

\section{An increasing problem}

The number of predatory publishers has exploded in the last decade, so it is increasingly important to be able to identify and avoid predatory publishers. 


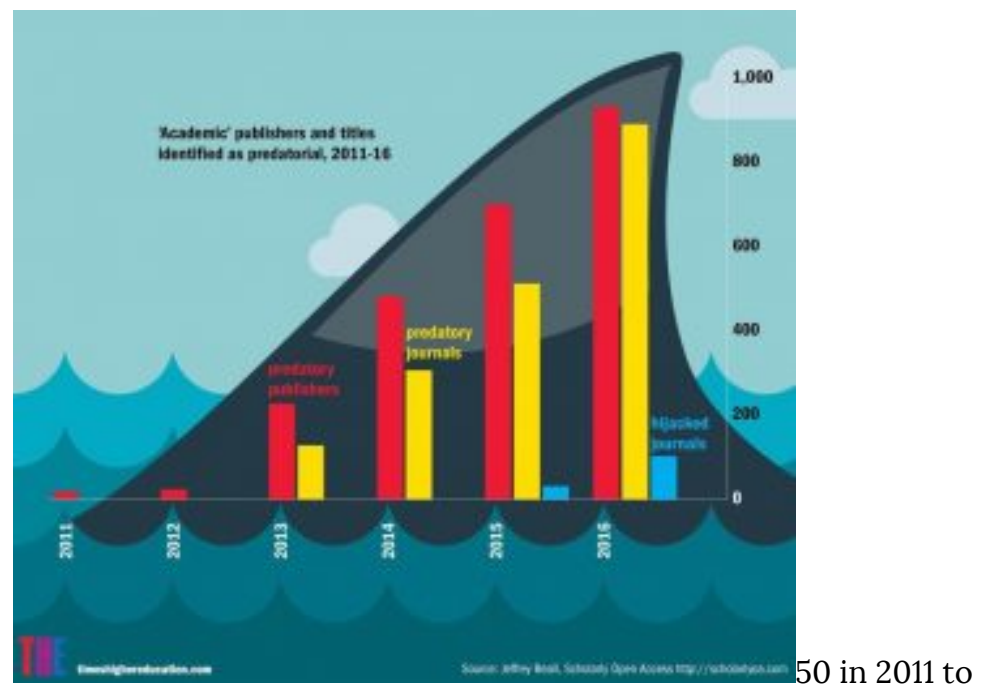

900 in 2016" width="422" height="363"

srcset="https://openeducationalberta.ca/advancedlibsearch/wpcontent/uploads/sites/63/2020/07/predpub-300x258.jpg 300w, https://openeducationalberta.ca/advancedlibsearch/wp-content/ uploads/sites/63/2020/07/predpub-768x660.jpg 768w, https://openeducationalberta.ca/advancedlibsearch/wp-content/ uploads/sites/63/2020/07/predpub-65x56.jpg 65w, https://openeducationalberta.ca/advancedlibsearch/wp-content/ uploads/sites/63/2020/07/predpub-225x193.jpg 225w, https://openeducationalberta.ca/advancedlibsearch/wp-content/ uploads/sites/63/2020/07/predpub-350x301.jpg 350w, https://openeducationalberta.ca/advancedlibsearch/wp-content/ uploads/sites/63/2020/07/predpub.jpg 838w" sizes="(max-width: 422px) 100vw, 422px">

Increase in predatory publications from 2011 to 2016

Why should you avoid predatory publishers?

Publishing in predatory publications: 
- Researchers will not be able to find your work, as predatory publishers are not included in academic databases

- People will not cite your work, as researchers avoid citing predatory publications

- Your work will not be peer-reviewed, as predatory publications to not go through a peer-review process

- You cannot republish your paper in a legitimate journal without significant changes, as journals will not publish work that has already been published

- Your reputation as a researcher will suffer

Citing predatory publications:

- This work is not peer-reviewed, so it is not up to the same standard of quality as peer-reviewed publications

- Many predatory publishers contain pseudo-science or incorrect information

- It reflects poorly on your work when you cite predatory publishers

- Citing predatory publishers lends them legitimacy 


\section{Open Access}

In order to understand how predatory publishers work, it is important to look at Open Access publishing.

\section{What is Open Access?}

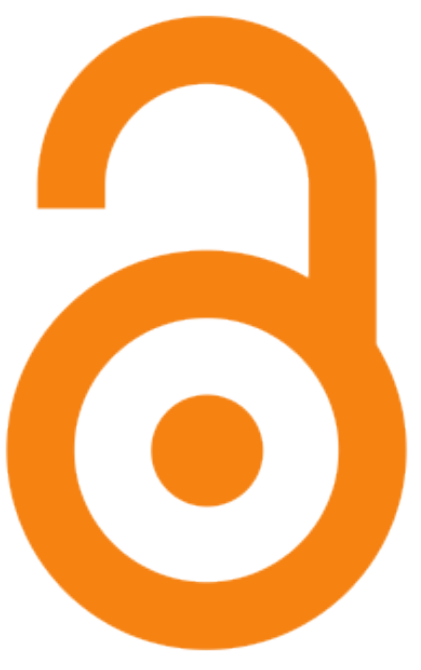

Open Access is the practice of providing free and unrestricted online access to research publications and data.

Open Access publishing allows researchers and the general public to access research publications freely, making it easier to disseminate and access research findings. 
Two types of Open Access Publishing: Gold and Green Open Access

\section{Gold Open Access:}

Publishing in a journal that offers immediate open access. Either an Open Access journal (where all papers are open), or a traditional journal where you have the option to make your article openly available. Most of these journals require Author Processing Charges (APCs).

\section{Green Open Access}

Deposit your paper in an open repository. Options include institutional repositories (such as the U of A's ERA) or discipline specific preprint servers (such as arXiv). You can share your work as a preprint any time, and many journals allow authors to deposit the accepted manuscript (or post-print) after an embargo period. You can check Sherpa/Romeo to determine if your chosen journal supports Open Access deposit.

\section{Why publish Open Access?}

There are many benefits to Open Access Publishing:

- You research can be disseminated faster when you share preprints (Green Open Access)

- This leads to faster impact 
- More people can access your research

- Open Access publications are free to all, unlike traditional publications that are behind a paywall

- Higher impact, faster

- Articles that are shared openly get more citations, faster than traditionally published articles

Sharing preprints is very common in physics and arXiv is the physics preprint server, but there are many other subject specific preprint servers that are relevant to interdisciplinary research.

Other preprint archives include:

- $\quad \underline{\text { bioRxiv }}$

- $\quad$ ChemRxiv

- $\quad$ medRxiv

\section{Open Access and predatory publishing}

Predatory publishers pretend to be legitimate Open Access publishers and take advantage of the "pay-to-publish" Gold Open Access model described above. They charge article processing fees, 
but do not have any of the editorial or peer-review processes that legitimate Gold Open Access publishers have.

Remember:

Open Access does not make a publisher predatory, their bad practices do! 


\section{Identifying Predatory Publishers}

Characteristics of Predatory Publishers

In order to avoid predatory publishers, you have to be able to identify them. If you are not familiar with a journal or it's publisher, evaluate it carefully.

Common characteristics of predatory publishers:

- Website design: amateurish or outdated webpage

- Journal metrics: a predatory journal will often list fake journal metrics like "impact index"

- Real journal metrics include: h-index, Journal Impact Factor

- Read more about journal-level metrics here: https://guides.library.ualberta.ca/research-impact/ journal-level-metrics

- Contact information: contact information for the journal is hard to find or there is no contact email

- Editorial board: there is little information about the editorial board

- Manuscript publication: guaranteed publication or an unrealistically short publication time is promised

- Journal may not be peer reviewed, or it my advertise a shortened peer review

- Journal focus: journal subject areas seem random and unrelated, or very broad

- Poor writing: errors or poor writing is present on the webpage or in articles, some articles may be plagiarized 
- Submission guidelines: guidelines are vague and short, may not mention peer review

- Solicitation: unsolicited emails asking for submissions, these emails often contain misleading information and may be poorly targeted to you

Note: if a journal has one of these characteristics, it is not necessarily predatory, but the more characteristics it has the more likely it is to be predatory.

How to check if a journal is predatory:

- Is the journal listed on the Directory of Open Access Journals (DOAJ)?

- This directory is a curated list of legitimate Open Access journals, however not all legitimate Open Access journals are listed here

- Check Beall's List

- Beall's List is a now-discontinued list of potential predatory publishers

- Ask a professor in your research area

- Your professor will know the best places to submit and the ones to avoid

- Ask your librarian for help

- Google it!

- Search the journal name and the word "predatory," take a look at the information that comes up 
Learn more about identifying predatory publishers:

Read the article The false academy: predatory publishing in science and bioethics for more characteristics of predatory publishers: https://dx.doi.org/10.1007/s11019-016-9740-3

Watch this video from the University of Manitoba for a good overview on identifying predatory publishers:

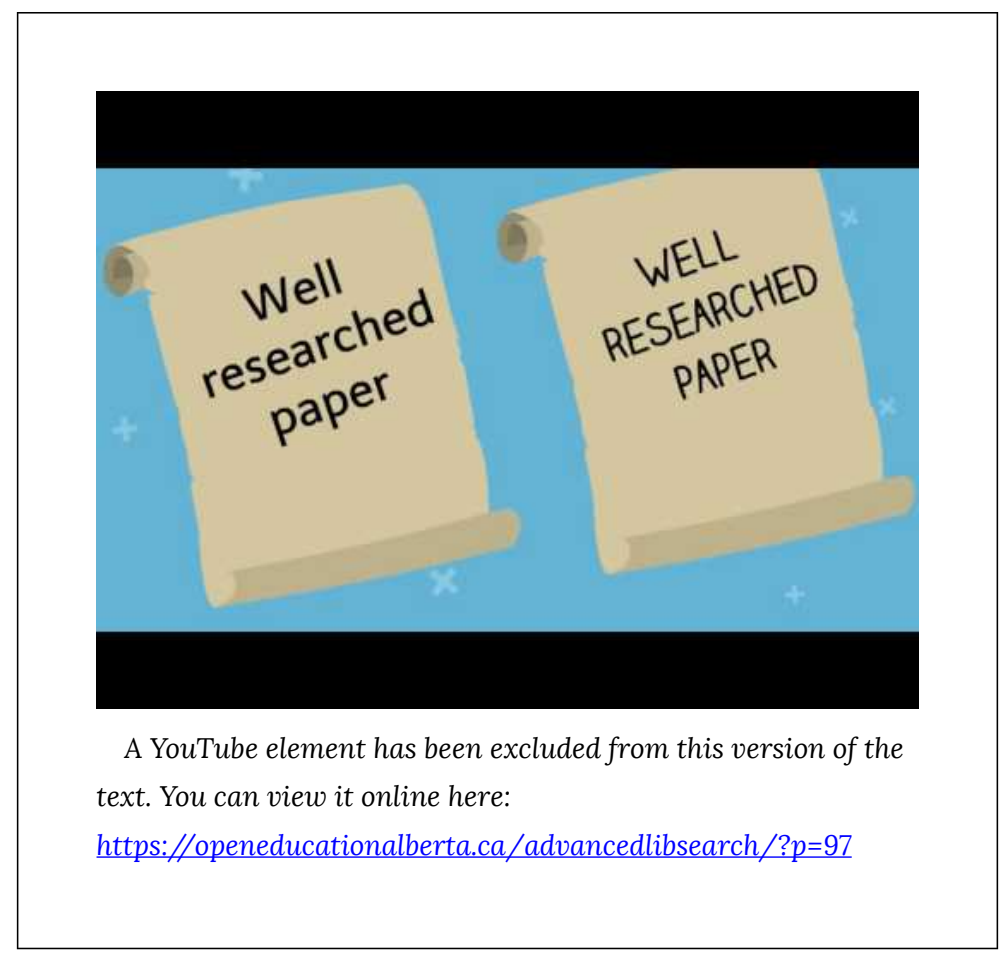

When in doubt, don't submit!

Identifying Predatory Publishers | 31 
If you are unsure about the quality of a journal, it is best to err on the side of caution. If you find evidence a journal may be predatory, but you are still unsure, be safe and choose another journal.

Read more about evaluating journals in the chapter Evaluating a Journal. 


\title{
9. Hijacked Journals
}

\author{
Hijacked Journals
}

Hijacked journals are predatory publications that are fakes or duplicates of legitimate journals. They take the title and information of a legitimate journal to make a fake journal and website to fool researchers into submitting to their predatory journal.

If you are looking at the website of a journal title you know is legitimate, but the website has some of the hallmarks of a predatory publisher (rapid publication or fast peer review) and charges a publication fee, double check that you are on the correct website.

\section{Example of a hijacked journal}

The journal Arctic, is a journal produced by the University of Calgary's Arctic Institute of North America (AINA). A hijacked version of this journal appeared a few years ago. Despite a ceaseand-desist from the University, the hijacked version still exists.

Learn more in this article from the CBC: https://www.cbc.ca/ news/canada/calgary/arctic-journal-university-calgary-fakepublication-scam-1.5138488

Let's look at the legitimate and predatory version of Arctic:

\section{Legitimate}




\section{国}

An interactive or media element has been excluded from this version of the text. You can view it online

here:

https://openeducationalberta.ca/advancedlibsearch/?p=104

https://arctic.ucalgary.ca/about-arctic-journal

\section{Hijacked}

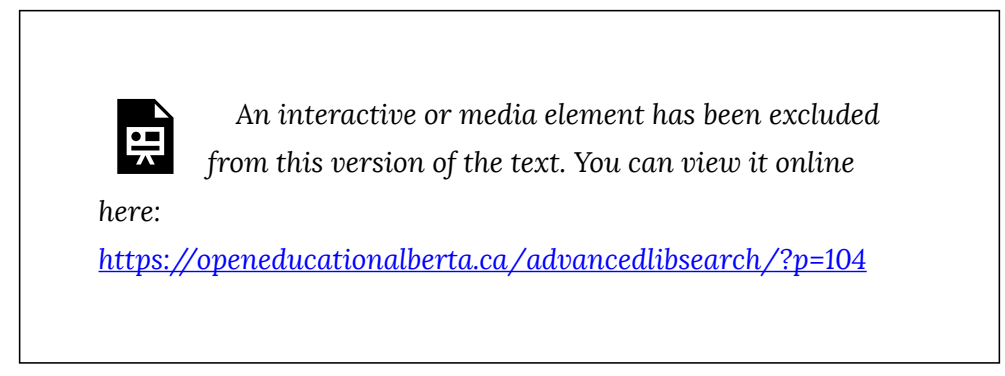

\section{https://www.arcticjournal.org/}

Take a look at the websites for these journals to see the difference between a legitimate and predatory journal

See another example of a hijacked journal here: https://publons.com/blog/hijacked-journals-what-they-are-andhow-to-avoid-them/ 
Think. Check. Submit!

When you are looking for a place to publish your work, always check before you submit. 

PART III

\section{ADVANCED LITERATURE SEARCHING}

This section will show you where and how to conduct your literature search along with recommendations for the most effective literature reviews 
Io. Where to Search

$\underline{\text { II. Building a Search }}$

I2. Searching Preprint Servers - arXiv

I3. Searching Academic Databases - Web of $\underline{\text { Science }}$

I4. Searching Google Scholar

I5. Recommended Databases by Discipline

I6. More Literature Searching Tips

17. Accessing Library Materials Remotely 


\section{Io. Where to Search}

\section{Learning Objectives}

After completing this section you be able to:

- $\quad$ Create an effective search strategy

- Identify appropriate databases and apply your search strategy to multiple databases

- $\quad$ Efficiently and comprehensively conduct your literature search 


\section{Searching for Articles}

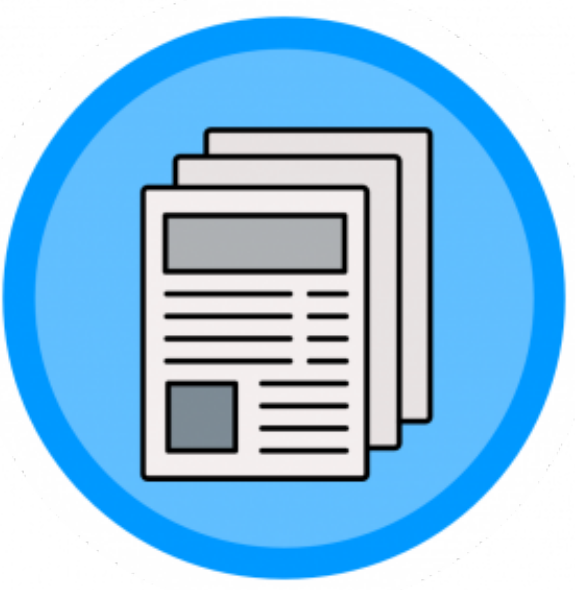

$\mathrm{T}$

here are three primary places to search for journal articles. This tutorial will cover the best ways to search each one:

1. Preprint servers

2. Academic databases

3. Google Scholar

There are pros and cons for each type of database. Where you search will depend on your needs and it is always recommended to search for information in more than one place (not every useful article will be found in every database).

Learn more about the different types of databases below: 


\section{Preprint servers (arXiv)}

Preprint servers are Open Access repositories of preprints. Preprints are the version of an article before it goes through the peer review process and publication. Preprint servers are typically moderated and screen the preprints that are submitted, but there is no formal peer review process. There are preprint servers for almost all academic disciplines. arXiv.org is the preprint server for physics.

Pros:

- Preprint archives contain the most up to date research, as preprints are

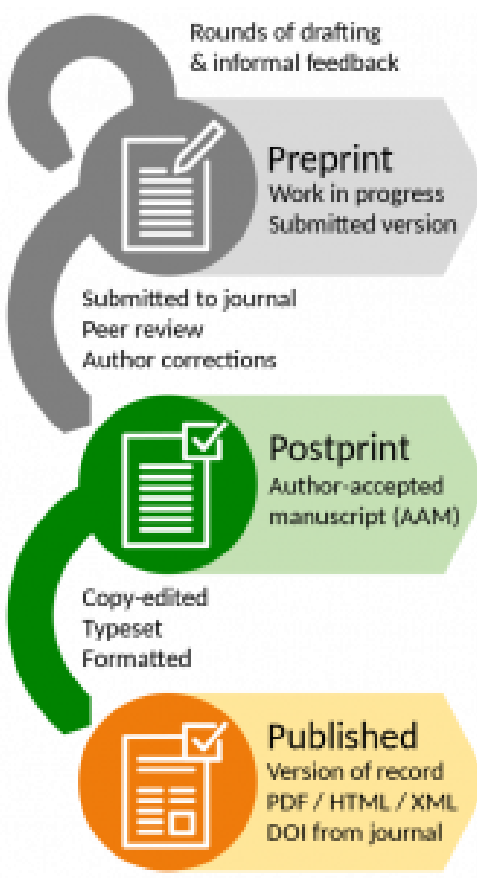

Preprints in the publication process shared before an article gets published

- arXiv is the best place to go for the most current physics literature

Cons:

- Preprints are not yet peer reviewed

- Though most preprints contain reliable information, some preprints do not

- Always check to see if the published version of a preprint is available, as that will be the final, updated version of the article

- Preprint archives do not contain as much older material and 
not every new article is released as a preprint

\section{Academic databases (Web of Science, Inspec, Scopus)}

Academic databases are collections of articles and other academic resources that are used for research. Many are subscription based (paid for by your library), but some are open access (like PubMed or the Astrophysics Data System). They contain peer reviewed articles and some academic databases also contain preprints. Academic databases can be interdisciplinary (Web of Science) or subject specific (GeoRef)

Pros:

\section{Clarivate Web of Science}

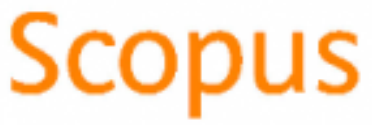

Academic databases contain the most search features and the most customizable search

- Academic databases can contain very old material, which is useful when searching for foundational articles

- Academic databases are the most reliable and are least likely to contain predatory articles

Cons:

- Most academic databases do not search preprints

- Many academic databases are not open access and require that users $\log$ in

42 | Where to Search 


\section{Google Scholar}

Google Scholar is a freely accessible database of scholarly literature. Unlike academic databases, Google Scholar does not vet the journals it includes.

Pros:

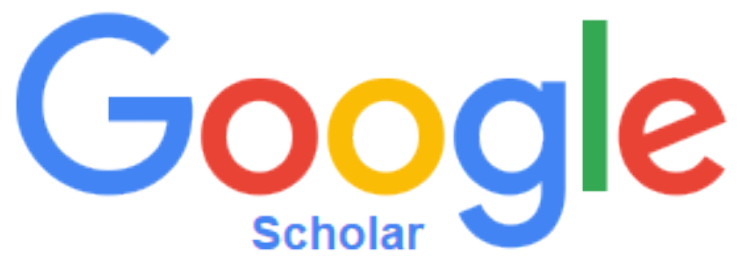

Google

Scholar is the largest database

Cons:

- Google Scholar has the simplest search and is unable to handle complex searches

- Google Scholar does not vet the material it includes so there is a higher chance of finding predatory articles

Searching for Books

Use the library catalogue to search for books and ebooks: 

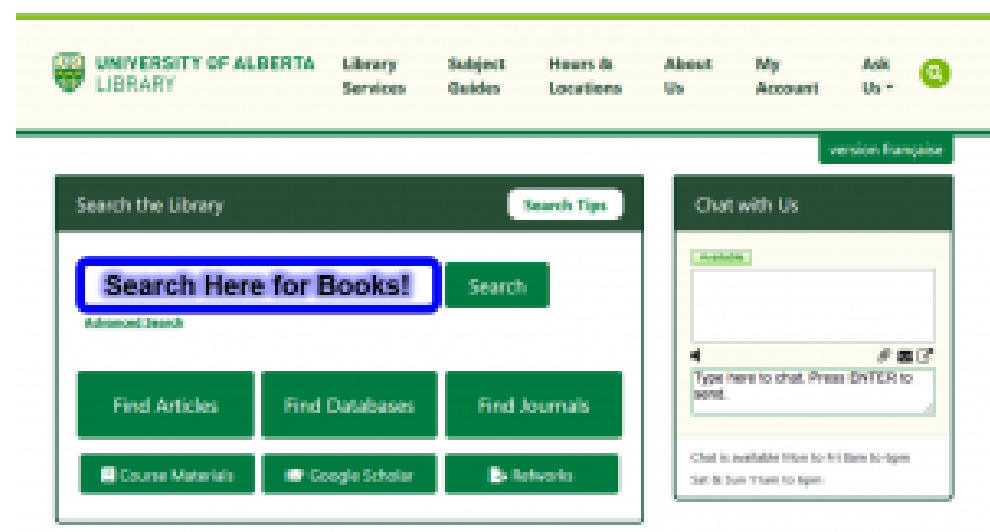

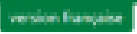

You can also search individual ebook collections. Some recommended ebook collections for physics are available here:

https://guides.library.ualberta.ca/physics/eresources 


\section{Building a Search}

The first step to searching any database is to build your search. In order to do the most effective literature search, you need to generate good search terms and combine them effectively. 



\section{Steps to a Search}

1. State your research topic

2. Identify the main concepts in your topic

3. Generate keywords for each concept

4. Build your search (using AND, OR)

5. Run search, evaluate and update

\section{State your research topic}

What are you interested in studying? What information do you want to find?

Topic: The development semiconductor nanowires for solar cells

\section{Identify the main concepts in your topic}

What are the key concepts? Look for subjects like "nanowires", not action words like "effect" or "impact" or "development"

The development semiconductor nanowires for solar cells

\section{Generate keywords for each concept}

How many ways can you state each concept? Look for synonyms, 
related or alternate words and make a list of all keywords for each concept

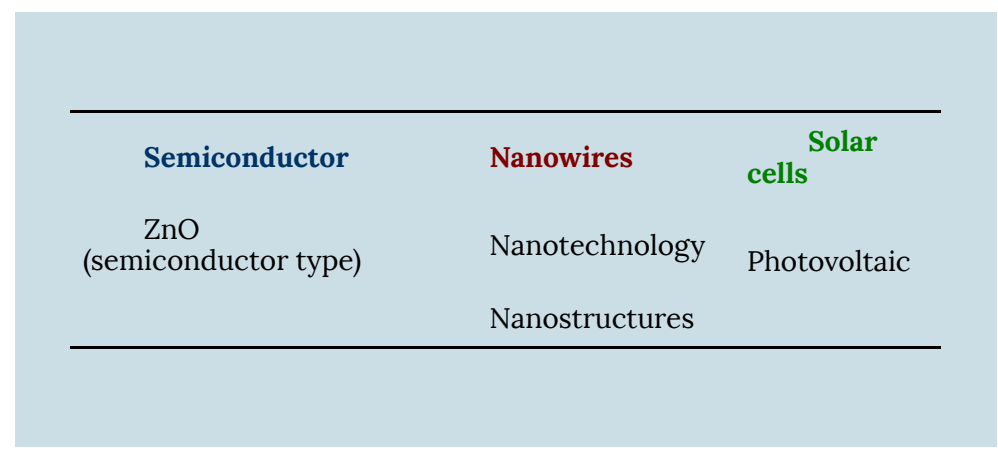

\section{Build your search (using AND, OR)}

Put your search together using AND and OR terms (also called boolean terms)

OR combines related words in a concept

OR gets you "more"

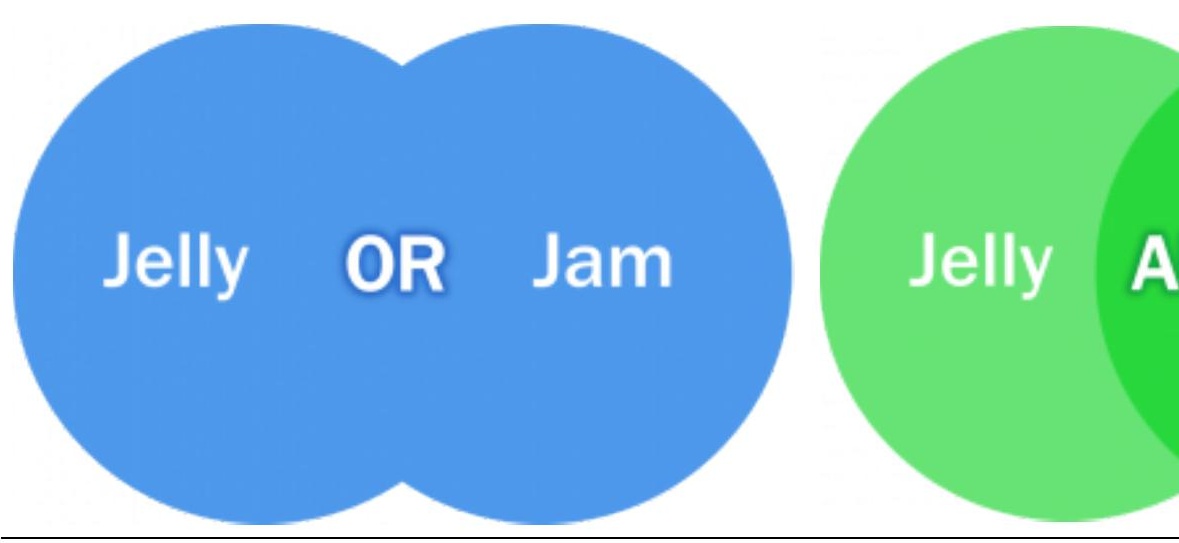

AND combine AND is "dema 
Final search:

(semiconductor OR ZnO) AND (nanowire* OR nanostructure* OR nanotech*) AND ("solar cell*" OR photovoltaic ${ }^{\star}$ )

Building a search:

- Truncation (*) - search all possible endings of a word

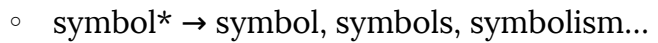

- Wildcard (?) - replace a single letter

- Wom?n $\rightarrow$ woman, women

- Phrases (") - search a phrase together

- "global warming" $\rightarrow$ finds exact phrase rather than "global" AND "warming"

- Parentheses () - keep OR terms together so that the search combines the OR terms before it adds the AND terms to the search

- (cat OR kitten) AND (dog OR puppy)

- Not all databases use parentheses (arXiv)

\section{Run search, evaluate and update}

Run your search in your database of choice. Take a look at your result lists, is it relevant? Look at individual search results for more potential keyword terms to add your search.

Common problems:

- Too many results 
- Try fewer OR terms or more AND terms

- Too few results

- Try more OR terms or fewer AND terms

- Use general keywords instead of specific

- Irrelevant results

- Check that you didn't truncate a word too soon (ie photo* will get me a lot of irrelevant results)

- Use more specific keywords instead of general

Next, update your search strategy and search again!

\section{Build your own search}

Build a search using a Search Strategy Worksheet

When you search, always keep track of the searches you have done, so that you don't need to repeat work later. Use the Search Strategy Worksheet, a search log or any other method to keep track of searches.

Search Log Example:

\begin{tabular}{llll}
\hline Database & Search & Date & Notes \\
$\begin{array}{l}\text { Web of } \\
\text { Science }\end{array}$ & $\begin{array}{l}\text { (semiconductor OR ZnO) AND } \\
\text { (nanowire* OR nanostructure* OR } \\
\text { nanotech*) AND ("solar cell*" OR } \\
\text { photovoltaic*") }\end{array}$ & Jun 7 & Too broad \\
Web of & $\begin{array}{l}\text { (semiconductor OR ZnO) AND } \\
\text { (nanowire* OR nanostructure* OR } \\
\text { nanotech*) AND ("solar cell*" OR } \\
\text { photovoltaic*) AND fabricat* }\end{array}$ & Jun 7 & $\begin{array}{l}\text { Good results } \\
\text { about } \\
\text { fabrication }\end{array}$ \\
\hline
\end{tabular}


- Keep track of your keywords and searches to save time and avoid repeated work

- Look at the terminology used in useful articles to add more terms to your search

- Always search in multiple databases

- Each database will look a little different, but we can transfer our search strategy to each database

- Searching is iterative! Search, look at your results, then update your search 


\section{I2. Searching Preprint Servers - arXiv}

\section{Searching Preprint Servers}

Preprint servers are best for finding the newest articles. However, deposit into preprint archives is voluntary and not every researcher shares their preprints. Sharing preprints is very common in physics, but less common in other diciplines. For a comprehensive literature search, you must search other databases in addition to preprint servers to find all of the articles you need.

Additionally, preprints are not peer reviewed. This means that the information in preprints has not been reviewed by experts. Always evaluate the information you read critically (use the CRAAP test).

See Chapter 15 for Recommended Databases by Discipline

\section{Searching in arXiv}

We will demo searching in arXiv, as it covers physics and related fields. We can apply the search strategy from the previous chapter to $\underline{\text { arXiv. }}$.

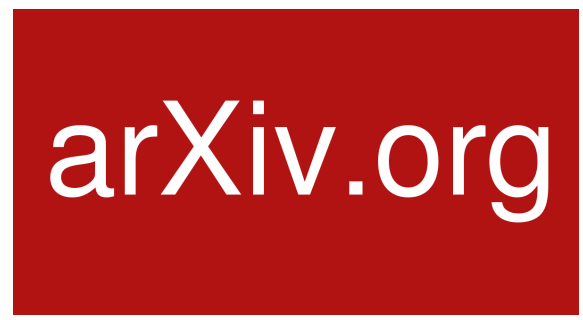

52 | Searching Preprint Servers arXiv 


\section{Advanced search}

The easiest way to search by research topic is through the advanced search function:

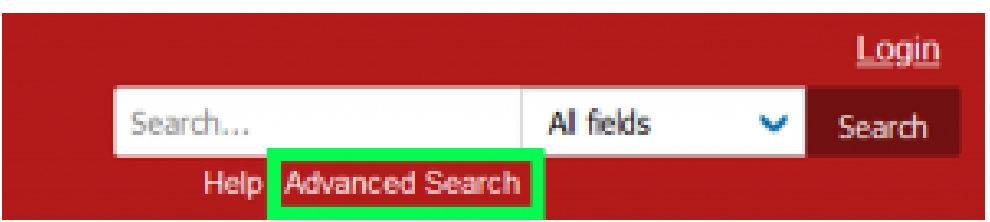

Click Advanced Search below the homepage search bar

Once you are in the advanced search, you can set your search up by adding new terms:

\section{Advanced Search}

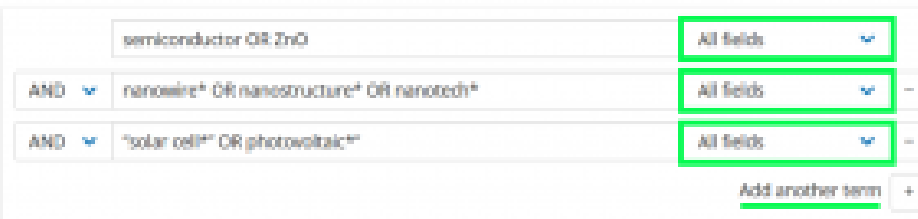

Each line represents a concept (the OR terms) and the lines are connected with AND

Note:

- Make sure to change the search field to "All Fields"

- The default is "Title" and "All Fields" will search both the title and abstract

- Do not use parentheses in the arXiv search bar

- You can customize and restrict your search with options on 
the advanced search page

- Click "add another term" to add another row for each concept you are searching

- The rows are automatically connected with AND terms

- The advanced search page also has a lot of great information on how to search arXiv

- Sort results by relevance to check how well your search returned relevant results

\section{More arXiv Tips}

\section{View final article}

When you find a preprint on arXiv that you want to use in your own work, always check whether there is a published version. The published version will be the most up-to-date version and it will be peer-reviewed.

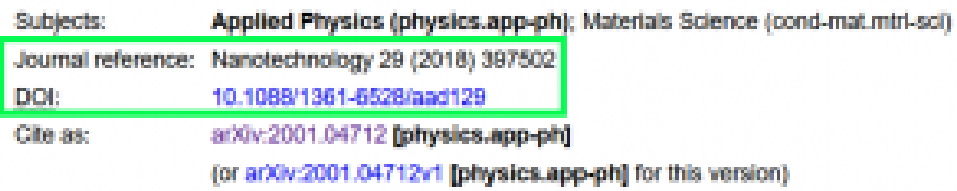

Look for the Journal Reference or DOI link

\section{Email alerts}

You can set up email alerts so that you are notified when new preprints are added to arXiv. You can customize your email alert to your subject area. This a great way to keep track of the newest research in your area.

54 | Searching Preprint Servers - arXiv 
Click the Subscribe button at the bottom of the page or go to https://arxiv.org/help/subscribe for instructions

\section{Subscribe}

Note: in bioRxiv and MedRxiv, look for a link that says "Alerts/RSS"

Tip

Always subscribe to preprint email alerts in relevant subject areas. This will let you see all new articles in your field without having to search for them. 


\title{
I3. Searching Academic Databases - Web of Science
}

\author{
Searching Academic Databases
}

Academic databases have the most features, making it easier to find relevant articles. There are two major interdiciplinary databases (Web of Science and Scopus) and many subject specific databases (Inspec for physics and engineering or GeoRef for geosciences). Almost all of these databases require a $\log$ in, as the library subscribes to them, thought some are Open Access.

Academic databases are the most comprehensive databases and many contain material going back over a hundred years. However, no one database has every article and some databases have better subject area coverage than others, so you should always search more than one database.

See Chapter 15 for Recommended Databases by Discipline

\section{Searching in Web of Science}

We will demo Web of Science as it is a large, interdisciplinary database with good coverage of sciences and medicine. Web of Science is actually a collection of databases, and it is best to search the full collection at once, using "All Databases." We can easily apply the search strategy developed in Chapter 9 to Web of Science: 


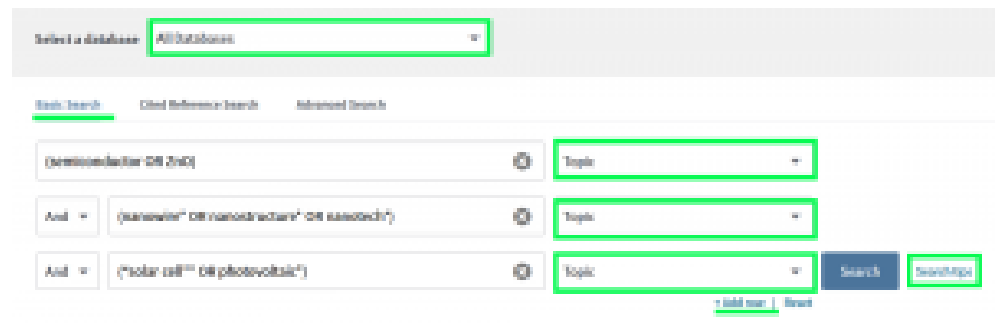

Each line represents a concept (the OR terms) and the lines are connected with AND

Note:

- Search "All Databases" as it searches every database in Web of Science. It includes the Web of Science Core Collection plus medical and biological databases

- Search by "Topic." Topic searches the title abstract and keywords of each article

- Click "add row" to add another row for each concept you are searching

- The rows are automatically connected with AND terms

- Click the "Search Tips" for a comprehensive list of search help

- Sort search results by relevance (default is sort by newest first)

\section{More Web of Science Tips}

\section{Search History}

Check your search history to keep track of the searches you do during a session.

To view your search history, click on Search History in the top right tool bar: 


\section{Tools - Searches and alerts - Search History Marked List}

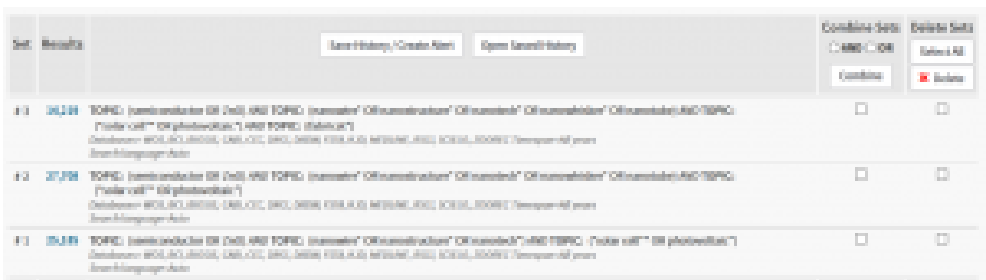

Search history showing three previous searches and the number of results for each. Click that number to view the search results.

Saved searches/ search alerts

You can save you searches to rerun later or you can set up a search alert. A search alert will send you an email when a new article that matches your search gets added to Web of Science. Always save your searches and once you have your best search, make a search alert. This will save you time and you won't need to repeat work to find new articles.

First make a Web of Science account:

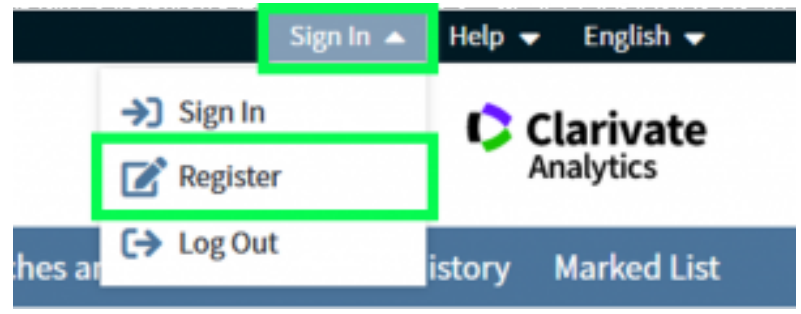

Look for the Sign In button in the top right tool bar

Next, go to your search history and click "Save History/Create Alert" 


\section{Save History / Create Alert \\ Open Saved History}

\section{Create alert}

\section{Alert Name}

\section{Nanowire solar cell seach}

Send me email alerts

Create alert

Cancel

To create and alert check "Send me email alerts" To save your search with no alert, uncheck "Send me email alerts"

To find your saved searches and search alerts, go to "Searches and alerts" in the top right tool bar. From there you can update alerts or rerun searches

\section{Tools - Searches and alerts - Search History Marked List}

\section{Citation information}

Web of Science (and Scopus) record the citations received by each resource. This means you can see who cited the articles in your search. Clicking the "times cited" for an article takes you to a list of 
every article that cited your article. This can help you find related articles and shows you newer articles you have have missed.

1. Flexible solar-cell from zinc oxide nanocrystalline sheets selt-assembled by an in-situ electrodeposition process

By: Xane, L. H.; Thu, P. X; Masuda, Y.; et al.

In your list of search results, each article includes the Times Cited

\section{Citation Network}

\section{In Web of Science Core Collection}

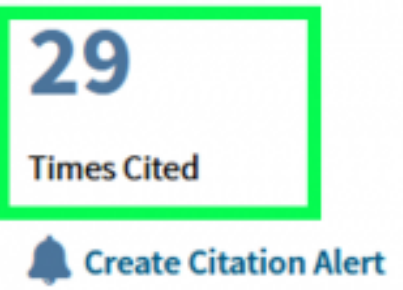

When looking at an article, the Citation Network sidebar includes the Times Cited 
Once you have a good search strategy, set up a search alert in either Web of Science or Scopus so that you know when new relevant papers get published.

Make sure to use the search history, saved searches or search alerts to keep track of your searches

Note: not all academic databases have search history, saved searches or search alerts. 


\section{I4. Searching Google Scholar}

Google Scholar

Google Scholar is the largest database, so you will be able to find the most articles through Google Scholar.

However, Google Scholar does not search like a regular database (nor does it search like Google). Additionally, Google Scholar does not vet the material in its search, so you are more likely to find nonacademic and predatory materials in Google Scholar.

Google Scholar can be very useful for quick searches, but it is not sufficient for an in depth literature review.

See Chapter 15 for Recommended Databases by Discipline

\section{Searching Google Scholar}

Google Scholar has a very simple search.

It does not use boolean terms (AND/OR) or truncation $\left({ }^{*}\right)$ and it does not have the same search as Google. Google's natural language search can correctly interpret a search phrased as a sentence or question. Google Scholar cannot do that, so we need to keep our searches simple. Additionally, Google Scholar's search is much less precise, so you will get more search results, but they will often be less relevant.

The best way to search Google Scholar is to keep your search simple and search one keyword for each concept at a time: 


\section{Google Scholar}

"concept 1" "concept 2 "concept 3 "

1. Generate the keywords for your search (see Building a Search)

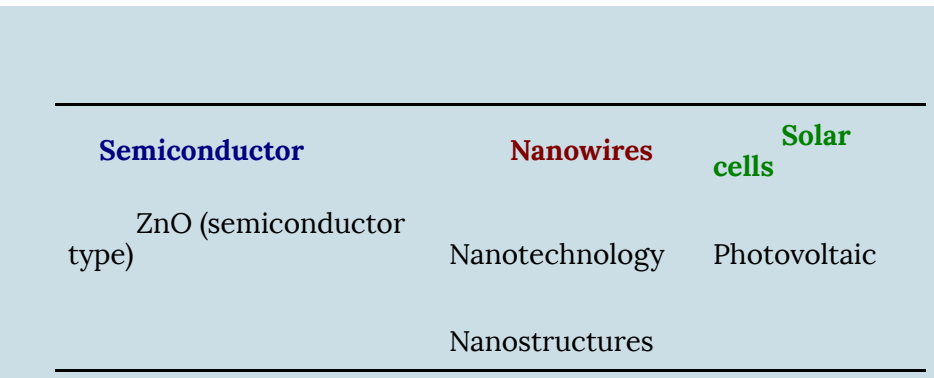

2. Choose one keyword for each concept and put them together semiconductor nanowire "solar cell"

3. Examine your results then try out different keyword combinations

\begin{tabular}{|l|l|}
\hline semiconductor nanowire pholovoltaic & Q \\
\hline semiconductor nanotechnology photovoltaic & $\mathbf{Q}$ \\
\hline ZnO nanowire photovoltaic & $\mathbf{Q}$ \\
\hline
\end{tabular}

4. Stop when you have found enough relevant articles.

Note: 
- Google Scholar will search every term you put in a search as though there is a boolean AND between each word

- Always check more than one page of Google Scholar Search results to find the information you need

- You can check who cited an article in Google Scholar by clicking "cited by" under each result

More Google Scholar Tips

\section{Search Alerts}

Create a search alert in the Google Scholar sidebar menu, by clicking "Alerts"

\section{$\equiv$ Google Scholar}

\& My profile

$\star \quad$ My library

(t.t) Metrics

\section{Alerts}

\section{Settings}

Click "create a new alert" and input your email address and the best search you tried 
Avarts

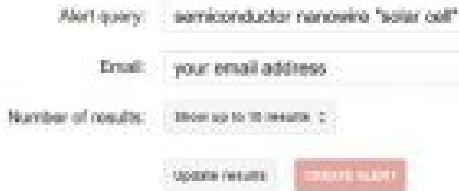

Searching Google Scholar | 65 


\section{I5. Recommended Databases by Discipline}

When you are conducting a literature review for a research project (499 project, Master's or PhD) you often need to search in multiple places to find all of the information you need. No single database contains every relevant article. In interdisciplinary work, it is particularly important to search in multiple databases.

Once you have developed a good search strategy, it is easy to convert that strategy from one database to another.

This page contains recommended databases for different disciplines of physics. It is recommended to search both general physics databases as well as discipline specific databases.

\section{General Physics}

The databases listed here cover physics and the many subdisciplines of physics. These databases will be a good source for all physics research.

Top Recommendations:

- arXiv: arXiv.org is an electronic archive and distribution server for open access preprint papers in physics, mathematics, computer science, quantitative biology and statistics.

- Web of Science: A major multidisciplinary database for the sciences and the social sciences, as well as a great research metrics tool. Contains coverage from the year 1900 to the present.

Other Recommendations: 
- Inspec: A database covering material in the fields of physics, electrical engineering and electronics, computers and control engineering, and information technology

- Scopus: The world's largest interdisciplinary literature database, including over 67 million journal records. Especially strong in science, engineering, technology, and medicine, with coverage from .

- CRC Handbook of Chemistry and Physics: The CRC Handbook is a comprehensive reference material containing property information and physical constants. Coverage includes physical constants of organic compounds, chemical properties, spectroscopy, atomic, molecular and optical physics, nuclear and particle physics, properties of solids, polymer properties, geophysics, astronomy, acoustics, health and safety information, and more.

\section{Astronomy and Astrophysics}

- Astrophysics Data System (ADS): ADS is a digital library portal for researchers in astronomy and physics. ADS contains more than 13 million records covering publications in Astronomy and Astrophysics, Physics, and the arXiv preprints.

- CDS Portal: The Strasbourg Astronomical Data Center (CDS) hosts the SIMBAD astronomical database; the VizieR astronomical catalogue service. and the Aladin interactive sky atlas. The CDS Portal searches these databases simultaneously using either object name or coordinates. CDS is best when searching for information and literature about specific astronomical objects.

- SIMBAD: SIMBAD is the world reference database for the identification of astronomical objects. SIMBAD provides basic data, cross-identifications, bibliography and measurements for astronomical objects. SIMBAD can be 
queried by object name, coordinates and various criteria.

- VizieR: VizieR provides the most complete library of published astronomical catalogues - tables and associated data - with verified and enriched data, accessible via multiple interfaces.

- NASA/IPAC Extragalactic Database (NED): NED is a comprehensive database of multiwavelength data and references for extragalactic objects, providing a information integrated from hundreds of large sky surveys and tens of thousands of research publications.

\section{Biophysics}

In biophysics it is important to search medical and biological literature in addition to physics literature.

- PubMed: PubMed comprises more than 30 million records for biomedical literature from MEDLINE, life science journals, and online books.

- medRxiv: medRxiv is a free online archive and distribution server for preprints in the medical, clinical, and related health sciences.

- bioRxiv: bioRxiv is a free online archive and distribution server for preprints in the biological and life sciences.

Note: both Web of Science (All Databases) and Scopus also include MEDLINE in their search, and Web of Science (All Databases) searches BIOSIS, a large biological sciences database. 


\section{Computational Physics}

- ACM Digital Library: The ACM Digital Library contains all Association for Computing Machinery (ACM) publications as well as a comprehensive bibliographic database focused exclusively on the field of computing and applied computer sciences

- IEEE Xplore: The IEEE Xplore digital library features scientific and technical content published by the IEEE (Institute of Electrical and Electronics Engineers). Thought it primary focuses on electrical engineering, it also has content covering computing sciences and physics.

\section{Condensed Matter Physics}

There is no database specifically targeted to condensed matter physics, but useful material can still be found in other physics databases.

- INSPIRE: INSPIRE primarily covers high energy physics, but also has some coverage of condensed matter physics.

\section{Geophysics}

- GeoRef: GeoRef (1785 to the present) includes international coverage of the earth sciences and all aspects of geology and geophysics. 


\section{Particle Physics}

- INSPIRE: INSPIRE is an information platform for high energy physics, comprising 8 interlinked databases on literature, conferences, institutions, journals, researchers, experiments, jobs and data. It is previously know as SPIRES. Additionally, INSPIRE contains arXiv preprints relevant to particle physics.

- CERN Document Server (CDS): The CERN Document Server contains records of about 700,000 CERN and non-CERN articles, preprints, theses.

For help adapting your search strategy to new database, check the database's help feature or contact your librarian 


\section{I6. More Literature Searching Tips}

\section{Keep Track of Your Searches}

Always keep track of your searches to avoid repeating work and make your literature search more efficient. Choose from the following methods:

- Search strategy worksheet - build your search and update your search strategy as you go

- Search log - use this template or make your own document to keep track of what you have searched and where

- Save searches - some databases will let you save your search history and set up search alerts

\section{Browse journals}

Make sure to examine the journals most relevant to your work. Browse new issues of relevant journals and search within these journals to relevant articles.

- Set up Table of Contents alerts for journals important to your work (see below in Alerts)

\section{Set up alerts}

Always set up alerts so that you receive updates on new publications. This is an easy way to both find new research on your topic and to keep up to date in your field of study. 
- Search alerts: set up a search alert in Web of Science or Scopus using your best search

- Preprint alert: set up an alert in the preprint servers for your subject area. Look for a link that says "alerts" or "subscribe"

- Table of contents alert: sign up for a table of contents (ToC) alert for journals important to your research. Most journals will let you sign up for an alert that emails you the table of contents for each new issue when it is published

\section{Forwards and Backwards Searching}

Forwards and backwards searching uses citations to look at who has cited a paper and what sources a paper cites

- Backwards searching: look at the reference list of an article to see the resources they used (look at resources "backwards" in time from the original article).

- Forwards searching: also called citation searching. Look at who has cited an article in Web of Science, Scopus or Google Scholar (look at resources "forwards" in time from the original article).

When you start your literature search, you can contact your librarian for more tips and strategies. This will ensure you have a comprehensive and efficient literature search. 
More Literature Searching Tips | 73 


\section{I7. Accessing Library Materials Remotely}

\section{Off Campus Access}

Access to many of the resources on the University of Alberta Library website is restricted to students, faculty and staff.

To access these materials at home, navigate to the e-journal or database you wish to use via the Library Home Page and log in using your Campus Computing ID and Password.

Trouble Shooting

\section{EZProxy Access}

The library provides off-campus access using out EZProxy server. When you access databases and materials through the library website, you will automatically be directed to the EZProxy log-in screen if you are off campus.

If you are unable to access an article or ebook and are hitting a paywall, follow these steps to check your access:

1. Check the web address of the item, does it have EZProzy in the URL?

(1) https://pubs.acs.org/doi/pdf/10.1021/bi8006143 国 …

Web address with no proxy

74 | Accessing Library Materials Remotely 
2. If there is no proxy in the URL, add the EZProzy prefix

To enable off-campus access to online resources, add the EZProxy prefix "https://login.ezproxy.library.ualberta.ca/ login?url=" before the web address.

For example, the following is a URL for an online article:

https://pubs.acs.org/doi/pdf/10.1021/bi8006143

Once the EZProxy prefix is included, the link will appear as follows:

https://login.ezproxy.library.ualberta.ca/ login?url=https://pubs.acs.org/doi/pdf/10.1021/bi8006143

\section{If the proxy is in the URL, but you do not have access to the item \\ If you have logged into the proxy, and you still do not have access, this means the library does not have access to the item you want. In order to get access to this item fill out an Interlibrary Loan request, and the library will loan a copy from another library (www.library.ualberta.ca/services/interlibrary-loan)}


If you have an article title, and you want to know if the library has access, try our new Request an Article Search

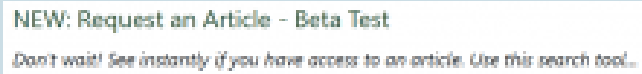

www.library.ualberta.ca/services/interlibrary-loan

For more information and help on off campus access, visit: https://www.library.ualberta.ca/services/off-campus-access 
PART IV

\section{CITATION MANAGEMENT AND AVOIDING PLAGIARISM}

This section will cover introduce citation management software and show you how to avoid plagiarism

I8. Citation Management

19. Citation Management with Zotero

20. Citing in LaTeX

$\underline{\text { 2I. Avoiding Plagiarism }}$ 



\section{I8. Citation Management}

After completing this section you will be able to:

- Use citation managers to effectively organize your citations

- $\quad$ Make sure you are citing properly

- Avoid plagiarism

Why do we cite?

It's important to cite sources you used in your research for several reasons:

- To back up your claims - show you've done proper research by listing sources you used to get your information

- To give credit - be a responsible scholar by giving credit to other researchers and acknowledging their ideas

- To avoid plagiarism - do not claim the words and ideas of other authors

Why do we use citation managers?

Citation managers are software that can help you: 
- Collect research materials

- Organize research materials

- Collaborate and share research materials

- Cite while you write in Word, Google Docs or Open Office

- Generate an up-to-date BibTeX file (.bib) to cite in LaTeX

It is highly recommended that you use a citation manager in your research

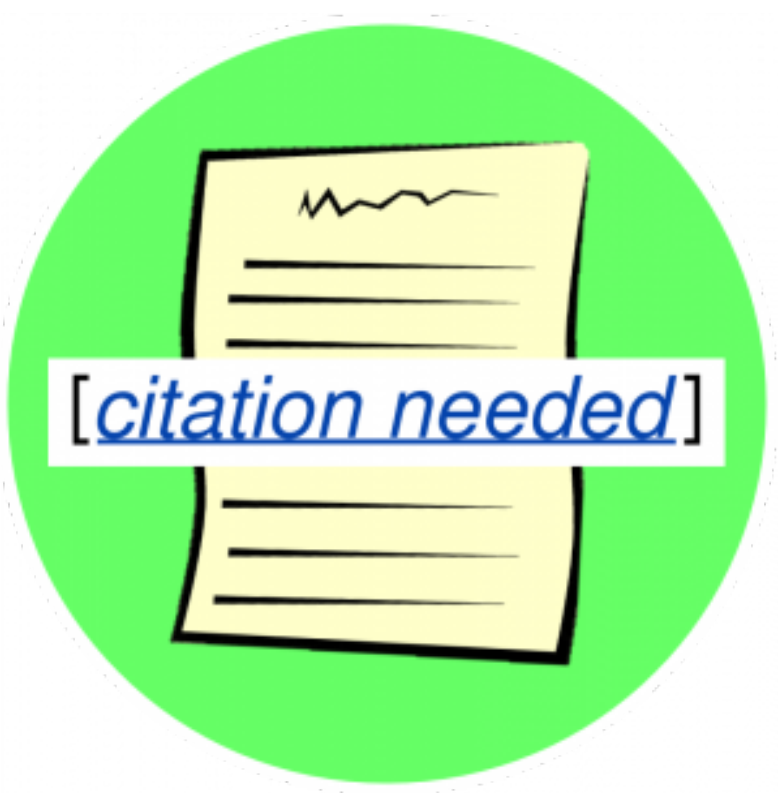




\section{I9. Citation Management with Zotero}

\section{Using Zotero}

There are many citation managers to chose from, but Zotero is recommended for the following reasons:

- Zotero is free (you can pay for more storage space)

- Zotero is open-source and run by a non-profit

- Many popular citation managers are run by publishers that use your data for profit

- Zotero has a great support

- Zotero is easy to use

\section{Download Zotero}

Download the two components of Zotero at https://www.zotero.org/download/

- Zotero Desktop: where you can see and organize your citations 


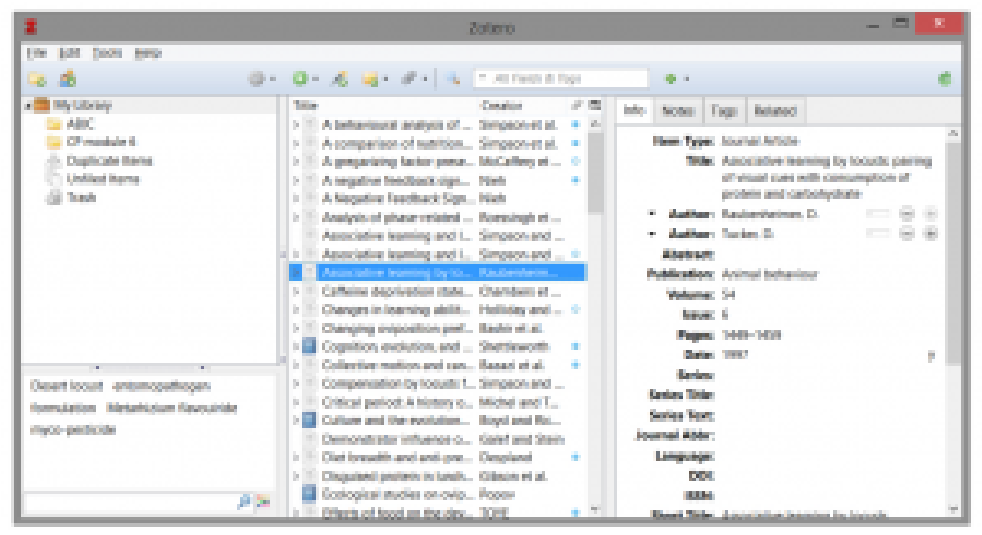

- Zotero Connector: a browser plugin that automatically detects content as you browse the web and allows you to save it to Zotero with a single click
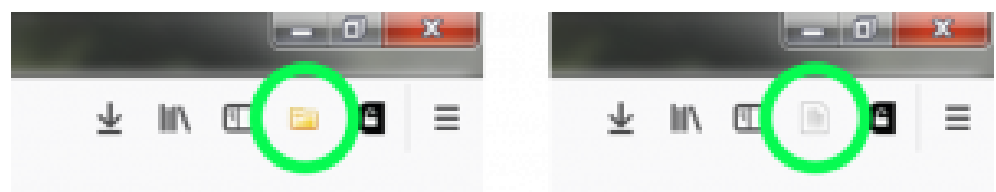

Zotero icon changes depending on what type of material you are looking at. A folder for a list of items and a paper for a journal article.

\section{Add items to Zotero}

There are two main ways to add item to Zotero

- Zotero Connector

- Use the Zotero button to automatically add materials to Zotoro

- If you are looking at a series of search results, you can bulk add to Zotero

- If you are on a webpage that includes the pdf of an article, 
Zotero will automatically download the article
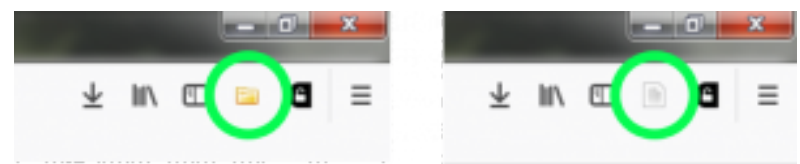

- Adding pdfs

- You can manually drag-and-drop pdfs into the main window of Zotero desktop to add those item to Zotero

\section{Organizing with Zotero}

In the Zotero desktop you can:

- Create folders to organize your resources

- Add tags and notes to items

- Search by keyword to find your resources

\section{Cite with Zotero}

To cite with LaTeX see the next chapter. To cite in Word or Open Office:

- Enable to Zotero plug in 
- Go to Tools > Add-ons and choose your plug in (you may need to restart your computer)

\section{Zotero}

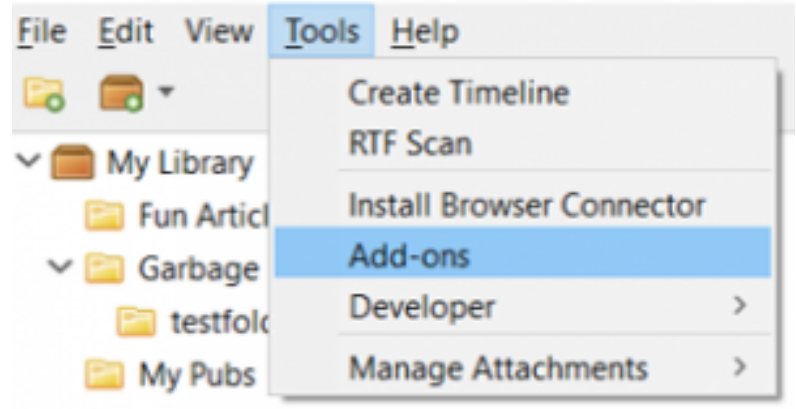

- Use the Zotero tool bar to add citations and create a bibliography

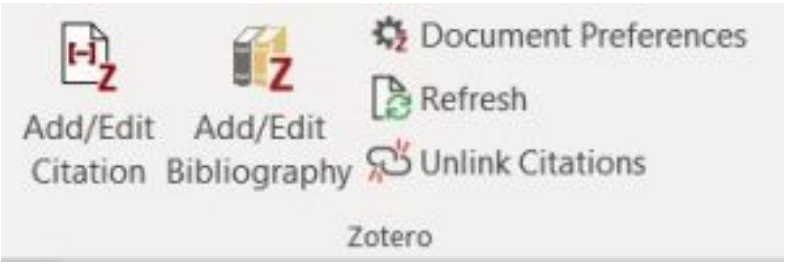

To cite in Google Docs:

- Using the Zotero connector will automatically add a Zotero menu in Google Docs

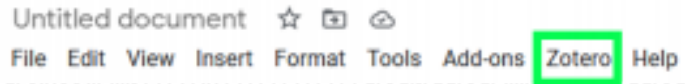

- Use the menu to add citations and create a bibliography 


\section{Zotero Help}

Zotero Quick Start Guide - Guide to help you get started with Zotero

Zotero Support - For more in depth help

Always double check that your citations are correct, even when you use a citation manager

- If a citation manager has the wrong information, you citation will be incorrect

- Always update or edit citation information in Zotero to correct your citation

- If you edit a citation in Word or Google Docs, the edit will be undone when you refresh. 


\section{Citing in LaTeX}

In LaTeX you cite using BibTeX. Bibliography entries are kept in a separate .bib file and then imported into the main LaTeX document.

You can either create your .bib file manually or use a citation manager to create one.

\section{Using Zotero With LaTeX}

Once you have all of the citation you need in Zotero, you can export them as a .bib file to use in LaTeX.

\section{Simple method}

In the simple method you export your chosen resources to a BibTeX file. With this method you bib will not automatically update. If you make any changes to items in Zotero or add new resources, you will need to re-export your BibTeX file

Export whole library

- Under the File menu, select "Export library..."

- On the next screen, choose format BibTex and click OK

- Navigate to the folder where you want to save your file, save it as filename.bib

Export selected items

- Select the items/resources you want to export in your Zotero library

- Right click and select "Export items"

86 | Citing in LaTeX 
- Select format BibTex and click OK

- Navigate to the folder where you want to save your file, save it as filename.bib

\section{Better BibTeX method}

With the alternate method, you download the Better BibTeX for Zotero extension. Better BibTeX can automatically create citation key for Zotero items and will synchonize you BibTeX files with the Zotero Library.

ven more compatible with BibTeX, by automatically creating citation keys for the documents, or synchronizing the BibTeX files with the Zotero library. 
2I. Avoiding Plagiarism

Plagiarism

Plagiarism is the action or practice of taking someone else's work, idea, etc., and passing it off as one's own; literacy theft (Oxford English Dictionary)

There are two types of plagiarism:

1. Intentional plagiarism - Intentional plagiarism occurs when one claims to be the author of work that they know was originally written completely or in part by someone else.

2. Unintentional plagiarism - Unintentional plagiarism occurs when a writer fails to follow to properly cite their sources without an explicit intent to cheat.

Take the following quiz to understand what counts as plagiarism

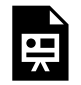
An interactive or media element has been excluded from this version of the text. You can view it online here:

https://openeducationalberta.ca/advancedlibsearch/?p=265

\section{Avoiding Plagiarism}

To avoid plagiarism you must always give proper credit when you 88 | Avoiding Plagiarism 
use an idea, image, quotation, or any other information created by someone else.

How to avoid plagiarism

- Start your work early

- Students often plagiarize when they do not have time to finish an assignment

- Direct quotations

- Quote no more words than necessary

- Cite any authors you quote

- Paraphrase

- Restate the ideas in an existing work while retaining the original meaning and level of detail

- Cite any authors you paraphrase

\section{Paraphrasing}

Paraphrasing is not just expressing ideas "in your own words," a writer must express the original idea in the context of their own writing.

- Paraphrasing is not just replacing words
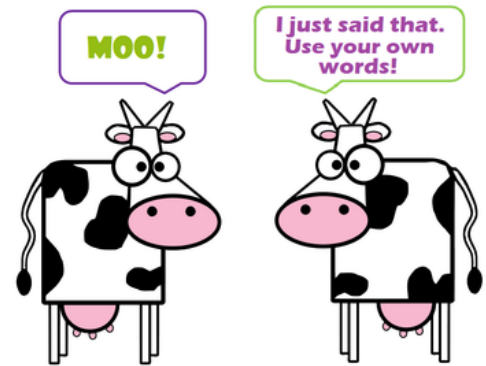

- It is still plagiarism to replace words in the From https://www.virtuallibrary.info/ original text with synonyms

- A good paraphrase changes the wording and the sentence structure

- Always cite your source

- Paraphrasing without citing the original source is 
plagiarism

90 | Avoiding Plagiarism 


\title{
For further library help:
}

\begin{abstract}
Ask Us!
Use the Ask Us! chat box on the library home page to get library help over chat or visit the Ask Us page to get help over chat, email or phone.

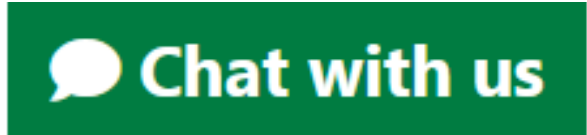

library.ualberta.ca/ask-us

$\sim \sim$

\section{Ask Your Librarian}

The physics librarian for the University of Alberta is Lauren

Stieglitz (hi!) 


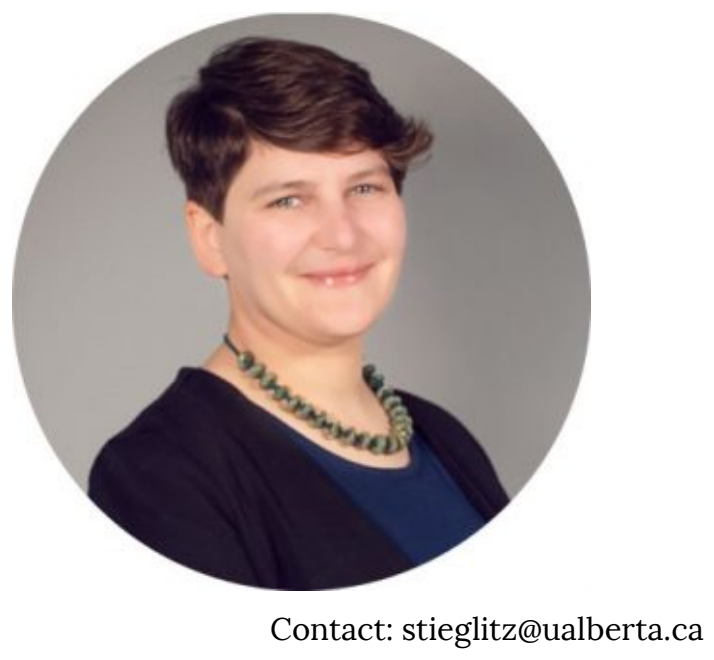

92 | Getting Help 